\title{
Pregnancy and Its Effect on the Progression of Diabetic Retinopathy
}

\author{
Jeff Van Impe, MD*
}

\section{INTRODUCTION}

Visual changes may occur during pregnancy (1). Women with type I diabetes are particularly vulnerable to ocular changes during pregnancy. Multiple studies have demonstrated that a worsening of retinopathy in diabetic patients can occur during pregnancy (2-9). The significance of this problem should not be overlooked considering the prevalence of diabetes and diabetic eye problems in North America. Diabetes is the leading cause of new cases of blindness in American adults between the ages of 20 and 74 (10). The incidence of diabetes has been found to be slightly higher in women than men (11), and the age-adjusted female-to-male ratio of blindness due to diabetes is 1.4:1 (10). In light of these statistics it is imperative that young diabetic women of childbearing age be examined by an ophthalmologist prior to pregnancy or at least in the first trimester (12).

In this article, the classification of diabetic retinopathy is reviewed together with the current understanding of the pathophysiology of its progression during pregnancy and the factors associated with this progression. A discussion of the optimal management of patients with diabetic retinopathy both before and after conception is provided.

\section{STAGES OF DIABETIC RETINOPATHY}

Before elucidating the factors associated with progression of retinopathy during pregnancy, it is beneficial to outline the stages of diabetic retinopathy. The most commonly used classification system, the Modified Klein Classification of Diabetic Retinopathy (13), contains eight levels and is outlined in Table 1.

\footnotetext{
* To whom correspondence should be addressed: Jeff Van Impe, 4045 Upper Middle Road Unit 29, Burlington, Ontario, L7M 4S8 Email: jjhsix@yahoo.com
}

\section{PROGRESSION OF DIABETIC RETINOPATHY DURING PREGNANCY}

Although some studies have suggested pregnancy does not alter the course of diabetic retinopathy (14, $15)$, the majority have demonstrated the opposite to be true. Reported rates of progression of retinopathy range from $5 \%-70 \%$ (2-9).

A cohort study, the Diabetes Control and Complications Trial (DCCT), performed a longitudinal analysis on 180 women who had 270 pregnancies and 500 women who did not become pregnant during an average of 6.5 years of follow-up (8). Fundus photography was performed every 6 months throughout the study period (8). All subjects recruited into the DCCT were 13-39 years of age and had had type I diabetes for 1-15 years (8). This study divided the patients into conventional and intensive treatment groups with respect to insulin therapy and made use of odds ratios. In the conventionally treated group the pregnant women were found to have a 2.48 -fold greater risk of worsening retinopathy during pregnancy (8). The DCCT found that the greatest risk of worsening retinopathy occurred during the 2nd trimester and persisted for as long as 12-months postpartum (8). In the intensive treatment group, the pregnant women had a 1.63-fold greater risk of worsening of retinopathy in the course of pregnancy (8). Axer-Siegel et al. (9) reported in a study of 22 women with diabetic retinopathy, those with nonproliferative diabetic retinopathy (NPDR) at the start of pregnancy 55\% experienced progression of their existing NPDR while $22.5 \%$ progressed to proliferative disease.

Fortunately, many studies have concluded that diabetic retinopathy which progresses during pregnancy has a high-rate of spontaneous resolution after delivery $(8,9)$, although the length of time required for resolution is variable. Axer-Siegel et al. (9) found that in 
Table 1. Modified Klein Classification of Diabetic Retinopathy

\begin{tabular}{|c|c|}
\hline LEVEL & DEFINITION \\
\hline 1.0 & No retinopathy \\
\hline 2.0 & Microaneurysms (1 or more) only \\
\hline 3.0 & $\begin{array}{l}\text { Microaneurysms and } 1 \text { or more of the following: } \\
\cdot \text { Retinal hemorrhage }<\text { standard photo \#2A } \\
\cdot \text { Hard Exudates (HE) < standard photo \#3 } \\
\cdot \text { Retinal infarcts questionably present } \\
\cdot \text { Intraretinal microvascular abnormalities (IRMA) questionably present } \\
\cdot \text { Venous beading (VB) questionably present } \\
\cdot \text { Small venous loops definitely present }\end{array}$ \\
\hline 4.0 & $\begin{array}{l}\text { Microaneurysms and } 1 \text { or more of the following: } \\
\cdot \text { Retinal hemorrhage }>\text { standard photo \#2A } \\
\cdot \text { HE > standard photo \#3 } \\
\text { - Retinal infarcts definitely present } \\
\text {-IRMA definitely present } \\
\cdot \text {-VB definitely present }\end{array}$ \\
\hline 5.0 & $\begin{array}{l}\text { In fields } 4 \text { through } 7 \text { only: } \\
\text { At least } 3 \text { of the following: } \\
\text {-Microaneurysms/retinal hemorrhage }>=\text { standard photo \#2A in } 1 \text { field or more } \\
\text {-Retinal infarcts in at least } 2 \text { fields } \\
\text {-IRMA definitely present in at least } 2 \text { fields } \\
\text {-VB definitely present in at least } 2 \text { fields } \\
\quad \text { Or } \\
\text {-IRMA present in } 4 \text { fields and >= standard photo \#8A in at least } 2 \text { fields }\end{array}$ \\
\hline 6.0 & $\begin{array}{l}\text {-New vessels on or within } 1 \text { disc diameter (DD) }<\text { standard photo \#10A } \\
\text { Or } \\
\text {-New vessels elsewhere or preretinal or vitreous hemorrhage, but level } 7 \\
\text { definition not met }\end{array}$ \\
\hline 7.0 & $\begin{array}{l}\text { Diabetic Retinopathy Study (DRS) high-risk characteristics include one or } \\
\text { more of the following: } \\
\cdot \text { New vessels elsewhere }>1 / 2 \text { disc area in any single photographic field when } \\
\text { associated with fresh vitreous or preretinal hemorrhage in any field } \\
\cdot \text { New vessels on or within } 1 \text { DD of the disc graded }<\text { standard photo \#10A } \\
\text { with preretinal or vitreous hemorrhage } \\
\cdot \text { New vessels on or within } 1 \text { DD of disc graded }>=\text { standard photo \#10A with } \\
\text { or without preretinal or vitreous hemorrhage }\end{array}$ \\
\hline 8.0 & $\begin{array}{l}\text { Unclassifiable due to large vitreous hemorrhage, Phthisis or enucleation } \\
\text { secondary to Diabetic Retinopathy }\end{array}$ \\
\hline
\end{tabular}

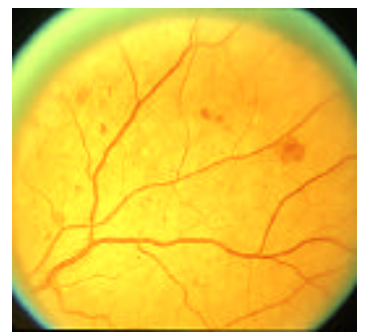

Standard Photo \#2A

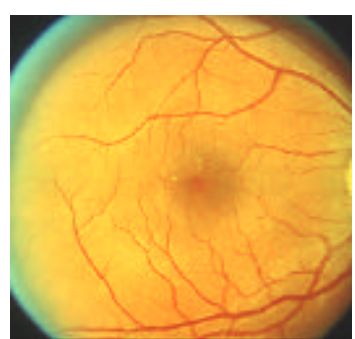

Standard Photo \#3

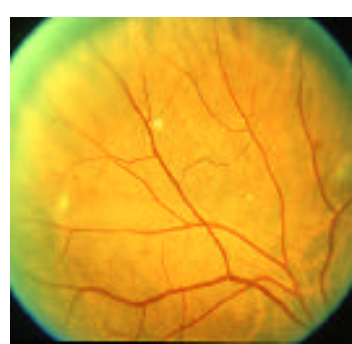

Standard Photo \#8A

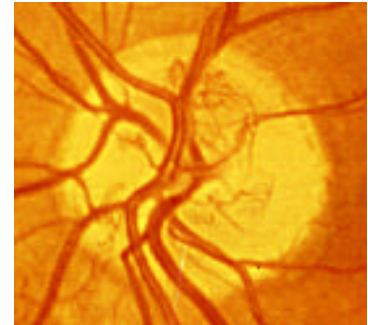

Standard Photo \#10A 
Table 2. Summary of the risk factors associated with the progression of diabetic retinopathy during pregnancy

\begin{tabular}{|l|l|}
\hline \multicolumn{1}{|c|}{ RISK FACTORS } & \multicolumn{1}{c|}{ SUMMARY } \\
\hline $\begin{array}{l}\text { The pregnant state } \\
\text { itself }\end{array}$ & $\begin{array}{l}\text {-Even when controlling for glycemic control, blood pressure and duration of } \\
\text { diabetes, the current pregnancy itself was a major risk factor for progression of } \\
\text { diabetic retinopathy }\end{array}$ \\
\hline Duration of diabetes & $\begin{array}{l}\text {-Women who have had diabetes longer are more susceptible to worsening of their } \\
\text { diabetic retinopathy during pregnancy } \\
\text {-Younger age at onset of diabetes is associated with increased incidence of } \\
\text { progression of retinopathy }\end{array}$ \\
\hline $\begin{array}{l}\text { Degree of retinopathy } \\
\text { at conception }\end{array}$ & $\begin{array}{l}\text {-Risk of worsening of retinopathy increased with increasing severity of retinopathy } \\
\text { at conception }\end{array}$ \\
\hline Glycemic Control & $\begin{array}{l}\text {-Rapid tightening of glycemic control during pregnancy is associated with a higher } \\
\text { risk of progression of retinopathy } \\
\text {-Higher glycosylated hemoglobin levels at conception are associated with higher } \\
\text { rates of progression of retinopathy }\end{array}$ \\
\hline $\begin{array}{l}\text { Coexisting } \\
\text { Hypertension }\end{array}$ & $\begin{array}{l}\text {-Progression of diabetic retinopathy is more likely to occur in patients with either } \\
\text { chronic hypertension or pregnancy induced hypertension } \\
\text {-Both elevated diastolic and systolic pressures have been independently associated } \\
\text { with DR progression }\end{array}$ \\
\hline
\end{tabular}

a subset of patients with no retinopathy at onset who went on to develop mild NPDR during pregnancy, 50\% had complete regression and $30 \%$ had partial regression of their disease after delivery. However, the rates of regression were reduced in patients with mild NPDR at onset. In this group only $17 \%$ had total regression to their baseline and $58 \%$ had partial regression (9). Although the DCCT Trial (8) demonstrated that the progression of retinopathy often continued into the first year postpartum, it was found that worsening of existing retinopathy during pregnancy had no long-term consequences as women who did and did not become pregnant during the study had similar retinopathy levels 6.5 years later.

\section{PATHOPHYSIOLOGY OF PROGRESSION}

Despite the preponderance of evidence suggesting worsening of diabetic retinopathy during pregnancy, the pathogenesis is still unclear. Several studies have examined retinal blood flow and vessel diameter in diabetic subjects during pregnancy (16-18). Chen et al. (16) studied retinal blood flow in pregnant females with and without diabetes and found a $14-19 \%$ increase in volume of retinal blood flow in diabetic patients who had progression of their diabetic retinopathy. Loukovaara et al. (17) also found, that when compared to nondiabetic pregnant women, retinal capillary blood flow was higher in diabetic women during pregnancy.
In women with diabetes, retinal capillary blood flow tended to increase during pregnancy until the 3rd trimester and to be lower 3 and 6 months postpartum, compared to capillary flow during the 3rd trimester (17). Chen et al. (16) proposed that the progression of diabetic retinopathy in pregnant diabetics may partly result from increased retinal blood flow caused by hyperperfusion. The ability of the retina to autoregulate its blood flow is impaired in diabetic retinopathy (16), and thus in a diabetic patient, the physiologic changes of pregnancy impose an added stress on an already compromised retinal circulation (16).

Conversely, Schocket et al. (18) found a decrease in retinal venous diameter and volumetric blood flow during the third trimester in both diabetic and nondiabetic mothers, with the decrease significantly larger in diabetics. This group theorized that the decrease in retinal blood flow may exacerbate retinal ischemia and hypoxia (18), leading to the progression of diabetic retinopathy.

\section{FACTORS ASSOCIATED WITH THE PROGRESSION OF DIABETIC RETINOPATHY DURING PREGNANCY}

Various factors have been shown to influence the progression of diabetic retinopathy during pregnancy. These include, but may not be limited to, the following: the pregnant state itself, duration of diabetes prior to the 
pregnancy, degree of retinopathy at time of conception, metabolic control before and during pregnancy, as well as the presence of coexisting hypertension. The factors involved are reviewed in detail below and summarized in Table 2.

\section{PREGNANCY}

Klein et al. (19) demonstrated in a 1990 study that after accounting for glycemic control, blood pressure and the duration of diabetes, the current pregnancy state itself was a major risk factor for progression of retinopathy. Furthermore, the DCCT found that pregnancy itself was related to changes seen in retinopathy (8).

\section{DURATION OF DIABETES}

Several studies have shown that women who have had diabetes longer are more susceptible to worsening of their diabetic retinopathy during pregnancy $(2,9,20)$. Axer-Siegel et al. (9) found that patients with progression of their retinopathy during pregnancy had diabetes for an average of 15.4 years ( \pm 5.3 years) compared to 10.86 years ( \pm 6.7 years) in those who did not have any progression. The findings of Temple et al. (2) supported this observation. Progression of retinopathy was significantly increased in women with duration of diabetes 10-19 years compared to those with duration less than 10 years. Ten percent of those with diabetes of duration 10-19 years demonstrated progression of their retinopathy, compared to $0 \%$ in the group with diabetes for less than 10 years (2). Similarly, an association has been demonstrated between younger age at onset of diabetes and increased incidence of progression of retinopathy. Lauszus et al. (20) found that in women who had progression of their retinopathy, the average age at onset of diabetes was significantly younger (14 \pm 8 years), compared to the group with no progression of their disease ( $19 \pm 8$ years). It has been suggested that women with type I diabetes be encouraged to plan pregnancies early in life if possible (20).

\section{DEGREE OF RETINOPATHY AT TIME OF CONCEPTION}

Another important risk factor in the progression of retinopathy during pregnancy is the degree of retinopathy prior to conception. The Diabetes in Early Pregnancy study (21) demonstrated that the risk of worsening retinopathy during pregnancy was increased with the severity of retinopathy at the time of conception. Of women with no retinopathy at baseline, $10.3 \%$ progressed to demonstrate some nonproliferative retinopathy. In women with nonproliferative retinopathy with microaneurysms only, $21.1 \%$ demonstrated some progression of their disease. And, in women with moderate-to-severe nonproliferative retinopathy, $54.8 \%$ demonstrated progression of their disease. Progression to proliferative retinopathy in the absence of initial nonproliferative retinopathy in early pregnancy is extremely rare. Temple et al. (2) have provided further support by demonstrating that progression of retinopathy was significantly more common in women with moderate or severe background diabetic retinopathy at conception compared with women with minimal or no retinopathy at conception ( $30 \%$ vs. $3.7 \%)$.

\section{GLYCEMIC CONTROL}

Glycemic control is generally better during pregnancy because more intensive therapy is undertaken in an attempt to minimize fetal and maternal complications (24). Interestingly, Chew et al. (21) found that a greater magnitude of improvement in glucose control during pregnancy is associated with a higher risk of progression of retinopathy, compared to those with a more moderate improvement. In the Diabetes in Early pregnancy study (21), worsening of retinopathy was associated with the largest improvement in glycosylated hemoglobin during pregnancy. Other studies have also found that intensive insulin therapy is often associated with worsening of retinopathy during the first year of treatment $(22,23)$, although these studies did not specifically deal with pregnant patients. Wang et al. (23) found that the deterioration is associated with an increased number of nerve fibre layer infarcts in the superficial layer of the retina. It has been suggested that intensive therapy may be associated with closure of small retinal vessels that were narrowed but previously patent. Correction of hyperglycemia results in decreased plasma volume which can put marginal vessels at risk (24). Whether the transient worsening of retinopathy during pregnancy is similar to that seen with the institution of intensive therapy (22, 23 ) is not clear. The above findings may provide a dilemma for the management of glucose levels, via insulin therapy, in pregnant diabetic women. The argument for excellent metabolic control prior to conception is also strengthened by the above findings (21).

Also, several studies have demonstrated that higher glycosylated hemoglobin levels at conception are associated with higher rates of progression of retinopathy. Temple et al. (2) found that in pregnant women who had progression of their retinopathy, the HbA1C was $7.5 \%$. Conversely, in pregnant women with no progression of their retinopathy the HbAIC was $6.6 \%$ at conception. Chew et al. (21) found that the rates of progression almost doubled in women with 
Table 3. Recommendations for the management of pregnant patients with Type I diabetes mellitus with the goal of decreasing the risk of progression of diabetic retinopathy

\begin{tabular}{|c|c|}
\hline Time Period & $\begin{array}{l}\text { Recommendations } \\
\end{array}$ \\
\hline Preconception & $\begin{array}{l}\text { Counsel diabetic women in childbearing years (especially those } \\
\text { with preexisting retinopathy) about the risk of progression } \\
\text {-Discuss postponement of conception until ocular disease is treated } \\
\text { and stabilized } \\
\text {-Diabetic patients should be brought under optimal glycemic } \\
\text { control prior to conception } \\
\text {-Counsel patients about the benefits of planning pregnancies early } \\
\text {-Comprehensive ophthalmologic examination to detect preexisting } \\
\text { retinopathy and define a baseline level }\end{array}$ \\
\hline First trimester (0-12 weeks) & $\begin{array}{l}\text { - Comprehensive ophthalmologic assessment } \\
\text {-Frequent monitoring of blood pressure } \\
\text {-Tight glycemic control: diet is first line and if blood glucose is } \\
\text { not well controlled, initiate insulin therapy }\end{array}$ \\
\hline $\begin{array}{l}\text { Second Trimester (12-28 weeks) } \\
\text { Third Trimester (28-40 weeks) }\end{array}$ & $\begin{array}{l}\text {-Comprehensive ophthalmologic examination at the discretion of } \\
\text { the examiner, but preferably every } 3 \text { months until delivery } \\
\text {-Continue to monitor blood pressure } \\
\text {-Tight glycemic control }\end{array}$ \\
\hline Postpartum & $\begin{array}{l}\text { Conflicting recommendations } \\
\text { Some sources suggest frequent ophthalmologic surveillance for } \\
\text { the first year postpartum }\end{array}$ \\
\hline
\end{tabular}

glycosylated hemoglobin levels greater than six standard deviations above the control mean. The results of these studies $(2,21)$ seem to also suggest the importance of controlling glycosylated hemoglobin levels prior to conception in diabetic women planning to have children.

It has been suggested that intensive therapy may be associated with closure of small retinal vessels that were narrowed but previously patent. Correction of hyperglycemia results in decreased plasma volume which can put marginal vessels at risk (24). The possible role of IGF-1 is supported by the clinical observation that retinopathy often worsens in the first year after the onset of intensive insulin therapy $(22,23)$, which increases serum IGF-1 concentrations $(22,23)$. The progression of retinopathy can be reversed by pituitary injury or hypophysectomy, which lowers serum IGF-1 concentrations (25).

\section{THE PRESENCE OF HYPERTENSION}

The progression of diabetic retinopathy is more likely to occur in patients with either chronic hypertension or pregnancy induced hypertension (9, 15, 19, 26). Lovestam et al. (9) found that pre-eclampsia was a potent risk factor for deterioration of retinopathy during pregnancy in type I diabetic patients. Both elevated diastolic and systolic blood pressure have been associated independently with diabetic retinopathy progression $(9,19)$.

\section{MANAGEMENT OF THE PREGNANT PATIENT WITH DIABETIC RETINOPATHY}

A consensus regarding the management of women with diabetic retinopathy who become pregnant is difficult to identify as many sources recommend slightly different strategies. A brief summary of recommendations for the management of diabetic patients with retinopathy who are planning a pregnancy or are already pregnant is presented in Table 3. It is very important to counsel diabetic women in childbearing years, especially those with pre-existing diabetic retinopathy, about the risk of progression of their disease while pregnant. Due to the fact that patients with severe nonproliferative diabetic retinopathy or proliferative retinopathy are at greatest risk for progression of their disease $(2,21)$ during pregnancy, postponement of conception should be considered until ocular disease is treated and stabilized (27). Furthermore, as the risk of progression of retinopathy during pregnancy is higher in patients with inadequate glycemic control $(8,21)$ and also in those who have rapid tightening of their glycemic control (21), it is recommended that diabetic patients be brought under tight glycemic control prior to conception (21). Also, 
since the risk of progression of retinopathy during pregnancy is greater in women who have had diabetes for longer periods of time $(2,9,20)$, it is beneficial to counsel women in their childbearing years about planning their pregnancies early (27), if possible.

The American Academy of Ophthalmology suggests guidelines for the monitoring of pregnant diabetic patients (28). They suggest that pregnant women should receive an ophthalmologic examination before conception (to determine baseline) and then again in the first trimester. Subsequent examinations should be at the examiners discretion, but preferably every 3 months until delivery.

This is in accord with the recommendations of The American Diabetes Association which recommends that women with preexisting diabetes who are planning a pregnancy should have a comprehensive eye examination and be counseled on the risk of development and/or progression of diabetic retinopathy (29). These women should have a comprehensive eye examination in the 1st trimester and close follow-up throughout pregnancy. It is important to note that these guidelines do not apply to pregnant women who develop gestational diabetes because such individuals are not at increased risk of developing retinopathy (29).

There is some discrepancy as to the frequency of eye examinations in pregnant women with diabetes. Several studies have shown that progression of retinopathy was seen most frequently in the second trimester $(3,8)$ and in most cases progression of retinopathy is present by the end of the second trimester (4). It is not clear how often patients will have no progression during the 1st trimester but then experience progression during the 2nd trimester. This group of patients may be missed by the above recommendations which state a comprehensive eye examination should be done in the 1 st trimester, with subsequent exams at the discretion of the examiner. Another source notes that the persistent effect of pregnancy on retinopathy progression requires continued frequent ophthalmologic surveillance for the first year postpartum (30).

\section{REFERENCES}

1. Sunness JS. The pregnant woman's eye. Surv Ophthalmol 32: 219-238; 1988.

2. Temple RC, Aldridge VA, Sampson MJ, Greenwood RH, Heyburn PJ, Glenn A. Impact of pregnancy on the progression of diabetic retinopathy in type I diabetes. Diabetic Medicine 18: 573-577; 2001

3. Moloney JBM, Drury MJ. The effect of pregnancy on the natural course of diabetic retinopathy. Am J Ophthalmol. 93: 745-756; 1982

4. Price JH, Hadden DR, Archer DB, Harley JM. Diabetic retinopathy in pregnancy. Br J Obstet Gynaecol. 91: 11-17; 1984

5. Klein BEK, Moss SE, Klein R. Effect of pregnancy on progression of diabetic retinopathy. Diabetes Care 13: 34-40; 1990
6. Dibble CM, Kochenour NK, Worley RJ, Tyler FH, Schwartz M. Effect of pregnancy on diabetic retinopathy. Obstet Gynaecol. 59: 699-704; 1982

7. Soubrane G, Canivet J, Coscas G. Influence of pregnancy on the evolution of background retinopathy. Int Ophthalmol Clin. 8: 249-255; 1985

8. The Diabetes Control and Complications Trial Research Group. Effect of pregnancy on microvascular complications in the Diabetes Control and Complications Trial. Diabetes Care 23: 1084-1091; 2000

9. Axer-Siegel R, Hod M, Fink-Cohen S, Kramer M, Weinberger D, Schindel B, Yassur Y. Diabetic retinopathy during pregnancy. Ophthalmology 103(11): 1815-1819; 1996

10. MMWR. Blindness caused by diabetes-Massachusetts, 19871994. MMWR-Morbidity \& Mortality Weekly Report 45: 937941; 1996

11. Trautner C, Icks A, Haastert B et al. Incidence of blindness in relation to diabetes. A population-based study. Diabetes Care 20: 1147-1153; 1997

12. Dinn RB, Harris A, Marcus PS. Ocular changes in pregnancy. Obstet Gynecol Surv. Feb 58(2):137-44; 2003

13. Klein R, Klein BEK, Magli YL, Brothers RJ, Meuer SM, Moss SE, David MD. An alternative method of grading diabetic retinopathy. Ophthalmology 93: 1183-1187; 1986

14. Lapolla A, Cardone C, Negrin P, Midena E, Marini S, Gardellin C, Bruttomesso D, Fedele D. Pregnancy does not induce or worsen retinal and peripheral nerve dysfunction in insulindependent diabetic women. J Diabetes Complications 12: 74-80; 1998

15. Lovestam-Adrian M, Agardh CD, Aberg A, Agardh E. Preeclampsia is a potent risk factor for deterioration of retinopathy during pregnancy in type I diabetic patients. Diabet Med. 14: 1059-1065; 1997

16. Chen HC, Newsom RS, Patel V, Cassar J, Mather H, Kohner EM. Retinal blood flow changes during pregnancy in women with diabetes. Invest Ophthalmol Vis Sci. 35(8): 3199-3208; 1994

17. Loukovaara S, Harju M, Kaaja R, Immonen I. Retinal capillary blood flow in diabetic and nondiabetic women during pregnancy and postpartum period. Invest Ophthalmol Vis Sci. 44(4):1486$1491 ; 2003$

18. Schocket LS, Grunwald JE, Tsang AF, DuPont J. The effect of pregnancy on retinal hemodynamics in diabetic versus nondiabetic mothers. Am J Ophthalmol. 128(4): 477-484; 1999

19. Klein BE, Moss SE, Klein R. Effect of pregnancy on progression of diabetic retinopathy. Diabetes Care 13(1): 34-40; 1990

20. Lauszus F, Klebe JG, Bek T. Diabetic retinopathy in pregnancy during tight metabolic control. Acta Obstet Gynecol Scand. 79(5): 367-370; 2000

21. Chew EY, Mills JL, Metzger BE, Remaley NA, JovanovicPeterson L, Knopp RH, Conley M, Rand L, Simpson JL, Holmes LB et al. Metabolic control and progression of retinopathy. The Diabetes in Early Pregnancy Study. National Institute of Child Health and Human Development Diabetes in Early Pregnancy Study. Diabetes Care 18(5): 631-637; 1995

22. Shamoon H, Duffy H, Fleischer N, Engel S, et al. The effect of intensive treatment of diabetes on the development and progression of long-term complications in insulin-dependent diabetes mellitus. N Engl J Med. 329(14): 977; 1993

23. Wang PH, Lau J, Chalmers TC. Meta-analysis of effects of intensive blood-glucose control on late complications of type I diabetes. Lancet 341(8856): 1306-1309; 1993

24. McCulloch DK. Pathogenesis and natural history of diabetic retinopathy. Up-To-Date Online V11.3. 2002 
25. Sharp PS, Fallon TJ, Brazier OJ, Sandler L, Joplin GF, Kohner EM. Long-term follow-up of patients who underwent yttrium-90 pituitary implantation for treatment of proliferative diabetic retinopathy. Diabetologia 30(4): 199-207; 1987

26. Rosenn B, Miodovnik M, Kranias G, Khoury J, Combs CA, Mimouni F, Siddiqi TA, Lipman MJ. Progression of diabetic retinopathy in pregnancy: association with hypertension in pregnancy. Am J Obstet Gynaecol. 166(4): 1214-1218; 1992

27. Sheth BP. Does pregnancy accelerate the rate of progression of diabetic retinopathy? Current Diabetes Reports 2(4): 327-330; 2002

Jeff Van Impe, MD, will be attending McMaster University for his first year of residency in Psychiatry. His research interests have shifted from Ophthalmology to substance abuse and addiction.
28. Diabetic Retinopathy. Preferred Practice Patterns (pamphlet). San Francisco, CA: The American Academy of Ophthalmology 13: $28 ; 1998$

29. Aiello LP, Gardner TW, King GL, Blankenship G, Cavallerano JD, Ferris FL 3rd, Klein R. Diabetic retinopathy. American Diabetes Association: Position Statement. Diabetes Care 23: S73-S76; 2000

30. Anonymous. Effect of pregnancy on microvascular complications in the Diabetes Control and Complications Trial. Diabetes Care 23: 1084-1091; 2000 